\title{
The contribution of Earth observation technologies to the reporting obligations of the Habitats Directive and Natura 2000 network in a protected wetland
}

\author{
Adrián Regos ${ }^{\text {Corresp., }}{ }^{1,2}$, Jesús Domínguez ${ }^{1}$ \\ 1 Departamento de Zooloxía, Xenética e Antropoloxía Física, Universidade de Santiago de Compostela, Santiago de Compostela, Spain \\ 2 Predictive Ecology Group, Centro de Investigacão em Biodiversidade e Recursos Genéticos da Universidade do Porto, CIBIO/InBIO, Vairão, Portugal \\ Corresponding Author: Adrián Regos \\ Email address: adrian.regos@usc.es
}

Background. Wetlands are highly productive systems that supply a host of ecosystem services and benefits. Nonetheless, wetlands have been drained and filled to provide sites for building houses and roads and for establishing farmland, with an estimated worldwide loss of $64-71 \%$ of wetland systems since 1900. In Europe, the Natura 2000 network is the cornerstone of current conservation strategies. Every six years, Member States must report on implementation of the European Habitats Directive. The present study aims to illustrate how Earth observation (EO) technologies can contribute to the reporting obligations of the Habitats Directive and Natura 2000 network in relation to wetland ecosystems.

Methods. We analysed the habitat changes that occurred in a protected wetland (in NW Spain), 13 years after its designation as Natura 2000 site (i.e. between 2003 and 2016). For this purpose, we analysed optical multispectral bands and water-related and vegetation indices derived from data acquired by Landsat 7 TM, ETM+ and Landsat 8 OLI sensors. To quantify the uncertainty arising from the algorithm used in the classification procedure and its impact on the change analysis, we compared the habitat change estimates obtained using 10 different classification algorithms and two ensemble classification approaches (majority and weighted vote).

Results. The habitat maps derived from the ensemble approaches showed an overall accuracy of $94 \%$ for the 2003 data (Kappa index of 0.93) and of 95\% for the 2016 data (Kappa index of 0.94). The change analysis revealed important temporal dynamics between 2003 and 2016 for the habitat classes identified in the study area. However, these changes depended on the classification algorithm used. The habitat maps obtained from the two ensemble classification approaches showed a reduction in habitat classes dominated by salt marshes and meadows (24.6-26.5\%), natural and semi-natural grasslands (25.9-26.5\%) or sand dunes (20.7-20.9\%) and an increase in forest (31-34\%) and reed bed (60.7-67.2\%) in the study area.

Discussion. This study illustrates how EO-based approaches might be particularly useful to help (1) managers to reach decisions in relation to conservation, (2) Member States to comply with the requirements of the European Habitats Directive (92/43/EEC), and (3) the European Commission to monitor the conservation status of the natural habitat types of community interest listed in Annex I of the Directive. Nonetheless, the uncertainty arising from the large variety of classification methods used may prevent local managers from basing their decisions on EO data. Our results shed light on how different classification algorithms may provide very different quantitative estimates, especially for waterdependent habitats. Our findings confirm the need to account for this uncertainty by applying ensemble classification approaches, which improve the accuracy and stability of remote sensing image 
classification. 
1 The contribution of Earth observation technologies to the reporting obligations of the

2 Habitats Directive and Natura 2000 network in a protected wetland

3

4

5

6 Adrián Regos ${ }^{1,2}$, Jesús Domínguez ${ }^{2}$

7

8

9 1Departamento de Zooloxía, Xenética e Antropoloxía Física, Universidade de Santiago de

10 Compostela, Santiago de Compostela, Spain.

11

$12{ }^{2}$ Predictive Ecology Group, Centro de Investigacão em Biodiversidade e Recursos Genéticos da

13 Universidade do Porto, CIBIO/InBIO, Vairão, Portugal.

14

15

16

17

18

19 Corresponding author: adrian.regos@usc.es

20

21

22

23

24 


\section{Abstract}

27 Background. Wetlands are highly productive systems that supply a host of ecosystem services

28 and benefits. Nonetheless, wetlands have been drained and filled to provide sites for building

29 houses and roads and for establishing farmland, with an estimated worldwide loss of $64-71 \%$ of

30 wetland systems since 1900. In Europe, the Natura 2000 network is the cornerstone of current

31 conservation strategies. Every six years, Member States must report on implementation of the

32 European Habitats Directive. The present study aims to illustrate how Earth observation (EO)

33 technologies can contribute to the reporting obligations of the Habitats Directive and Natura

342000 network in relation to wetland ecosystems.

35 Methods. We analysed the habitat changes that occurred in a protected wetland (in NW Spain),

3613 years after its designation as Natura 2000 site (i.e. between 2003 and 2016). For this purpose,

37 we analysed optical multispectral bands and water-related and vegetation indices derived from

38 data acquired by Landsat 7 TM, ETM+ and Landsat 8 OLI sensors. To quantify the uncertainty

39 arising from the algorithm used in the classification procedure and its impact on the change

40 analysis, we compared the habitat change estimates obtained using 10 different classification

41 algorithms and two ensemble classification approaches (majority and weighted vote).

42 Results. The habitat maps derived from the ensemble approaches showed an overall accuracy of $4394 \%$ for the 2003 data (Kappa index of 0.93 ) and of $95 \%$ for the 2016 data (Kappa index of

44 0.94). The change analysis revealed important temporal dynamics between 2003 and 2016 for

45 the habitat classes identified in the study area. However, these changes depended on the

46 classification algorithm used. The habitat maps obtained from the two ensemble classification

47 approaches showed a reduction in habitat classes dominated by salt marshes and meadows (24.6- 
$4826.5 \%)$, natural and semi-natural grasslands (25.9-26.5\%) or sand dunes (20.7-20.9\%) and an 49 increase in forest (31-34\%) and reed bed (60.7-67.2\%) in the study area.

50 Discussion. This study illustrates how EO-based approaches might be particularly useful to help

51 (1) managers to reach decisions in relation to conservation, (2) Member States to comply with

52 the requirements of the European Habitats Directive (92/43/EEC), and (3) the European

53 Commission to monitor the conservation status of the natural habitat types of community interest

54 listed in Annex I of the Directive. Nonetheless, the uncertainty arising from the large variety of

55 classification methods used may prevent local managers from basing their decisions on EO data.

56 Our results shed light on how different classification algorithms may provide very different

57 quantitative estimates, especially for water-dependent habitats. Our findings confirm the need to

58 account for this uncertainty by applying ensemble classification approaches, which improve the 59 accuracy and stability of remote sensing image classification.

60

61

62

63

64

65

66

67

68

69

70

71

72 wetlands have been perceived as a source of vectors of waterborne infectious diseases, and

73 historically considered worthless and an impediment to development. Consequently, wetlands 
74 have been drained and filled to provide sites for building houses and roads or for establishing

75 farmland, with an estimated worldwide loss of 64-71\% of wetland systems since 1900

76 (Davidson, 2014).

77

78

79

80

81

82

83

84 85

86

87

88

89

90

91

92

93

94

95 96

\section{1}

Protection for wetlands can come in many forms, ranging from local practices and national legislation to international recognition through inscription on the Ramsar List and/or the World Heritage List (Thorsell, Levy \& Sigaty, 1997). In Europe, the Natura 2000 network is the cornerstone of current environmental conservation strategies. This network includes Special Protection Areas for wild birds (SPAs), designated by the Member States under the Birds Directive (2009/147/EC) with the aim of conserving the habitats of particularly threatened species and migratory species. It also includes Special Areas of Conservation (SACs), designated for other taxa and habitats under the Habitats Directive (92/43/ EEC). Every six years, Member States must report on implementation of the measures taken under these European Directives. This report must include information on the conservation measures concerning the natural habitat types listed in Annex I of the Habitats Directive (Art. 6), as well as evaluation of the impacts and surveillance (Art. 2) of those measures in relation to their conservation status, with particular regard to priority natural habitat types and priority species.

Earth observation (EO) technologies have made significant contributions to nature conservation in the last few decades (Muchoney, 2008; O’Connor et al., 2015 and reference therein). Increasingly large amounts of geospatial information are being provided by satellite and aerial image processing and analysis - also known as remote sensing (RS) - which has enormous potential for conservation applications (Leyequien et al., 2007; Alcaraz-Segura et al., 2009; 
97 Petrou, Manakos \& Stathaki, 2015; Skidmore et al., 2015; Adamo et al., 2016, among others).

98 Access to EO data has improved greatly in recent years, and many aerial and satellite data are

99 now freely available (Turner et al., 2015).

100

101

Despite the above-mentioned progress, the lack of a single, unifying habitat feature as

102

well as the highly dynamic nature of wetlands (which may lead to highly variable spectral

103

signatures) and their steep environmental gradients (which often produce narrow ecotone areas)

104 may constrain and overwhelm the capacity of current remote sensors (Gallant, 2015). Recent

105 advances in computing and the development of image classification techniques have made RS-

106 based land-cover mapping easier, faster and more widely available for use in both conservation

107 and applied ecology (Khatami, Mountrakis \& Stehman, 2016). Faced with this wide range of

108 techniques, many researchers have focused on comparing the image classification performance

109 of land-cover mapping or other applications (e.g. Hubert-Moy et al., 2001; Cracknell \& Reading,

110 2014; Regos et al., 2015). One effective solution for dealing with the uncertainty arising from the

111 use of a wide range of techniques is to generate a classification ensemble by combining some

112 individual classifiers. This is referred to as a multiple classification system or ensemble

113 classification approach (for a review, see Du et al., 2012). The ensemble classification approach,

114 recently applied by the remote sensing community, is viewed as an effective way of improving

115 the classification performance of remotely sensed imagery (Briem, Benediktsson \& Sveinsson,

116 2002; Lu \& Weng, 2007).

117

118

The main goal of the present work is to illustrate how EO technologies may contribute to

119 the reporting obligations of the Habitats Directive and Natura 2000 network regarding wetland 
120 ecosystems. We analysed the habitat changes that had taken place in a protected wetland (in NW

121 Spain), 13 years after its designation as Natura 2000 site (2003-2016). For this purpose, we

122 analysed optical multispectral bands and water-related and vegetation indices derived from data

123 captured by Landsat 7 TM, ETM+ and Landsat 8 OLI sensors. To quantify the uncertainty

124 arising from the algorithm used in the classification procedure and its impact on the change

125 analysis, we compared the habitat change estimates obtained using 10 different classification

126 algorithms and two ensemble classification approaches.

127

128 Material \& Methods

129 Study site

130 The study area is a coastal wetland included in the Natura 2000 network in 2003 and designated 131 as Special Area of Conservation (SAC) and Special Protection Area (SPA) for wild birds. The 132 site covers an area of 984 ha, corresponding to the boundaries of the "Dunas de Corrubedo e 133 lagoas de Carregal e Vixán” Natural Park (Fig. 1). The international importance of the wetland 134 was recognised when it was designated a Ramsar site, in 1993.

135

136

137 138
This wetland includes one of the largest dune systems in the NW Iberian Peninsula, with extensive stretches of sand (Ladeira, Ferreira and Vilar beaches) flanked by large dune and coastal lagoon ecosystems (Lagunas de Carregal and Vixán), together with an adjacent dune system, and an embryonic shifting dune (1-km long, 200-250 m wide and 12-15 m high) (Vázquez-Paz \& Pérez-Alberti, 2002). The dune system, comprising a sandy barrier, has favoured the creation of an interior sedimentary area composed of fixed dunes ('grey dunes'), marshes, sandy and muddy intertidal zones, as well as two coastal lagoons with very different 
143 aquatic characteristics: 1) the Carregal lagoon covers an irregular, delimited space between the

144 marsh and the dune system. The area adjacent to the coastline corresponds morphologically to an

145 estuarine channel covered by sandy deposits where flooding depends on the tidal cycle (Fig. 1);

146 2) the Vixán lagoon, located in the area distal to the coastline, has a dense reed bed (Phragmites

147 australis) that occupies most of the eulittoral and supralittoral environments (Fig. 1). In the area

148 adjacent to the coast, the reed bed is replaced by bulrushes (Typha latipholia) and, to a lesser

149 extent, by wet grasslands. The drainage channel zigzags through the dune system until reaching

150 the beach (Ramil-Rego, 2007).

151

152 Pre-processing EO data

153 We used satellite remote sensing imagery to map and monitor the habitat changes that have taken

154 place between 2003 and 2016. We analysed optical multispectral bands (Path/Row: 205/30)

155 derived from four cloud-free images acquired by NASA's Landsat missions on 20 March

156 (Landsat 7 ETM+) and 6 October 2003 (Landsat 5 TM) and on 2 May and 23 September 2016

157 (Landsat 8 OLI) (detailed information available for each band is available at:

158 http://landsat.usgs.gov/band_designations_landsat_satellites.php). Landsat scenes captured in

159 spring and autumn (e.g. in May and September) were analysed to take into account seasonal

160 differences in vegetation phenology (e.g. common reed grass). The images are all available free

161 of charge from the U.S. Geological Survey (USGS) Centre for Earth Resources Observation and

162 Science (EROS) and were obtained by direct download from the GloVis facility 163 (http://glovis.usgs.gov).

164 
All downloaded images were L1T (a processing level that includes a geometric correction

166 performed with ground control points and the use of a digital elevation model) and projected in

167 the UTM coordinate system (WGS 84 datum, UTM projection, Zone 29 North). Digital numbers

168 (DNs) were converted to top-of-atmosphere radiance and physically meaningful units by

169 radiometric calibration and application of sensor- and band-specific calibration parameters. The

170 classification process was based on the radiometric information obtained from reflective bands

171 and two multispectral indices for each image: 1) the Normalized Difference Vegetation Index

172 (NDVI; Rouse et al. 1974) and 2) the Normalized Difference Water Index (NDWI; Gao 1996).

173 This procedure enhanced the spectral separability of vegetation associated with aquatic and

174 halophilic environments.

175

176 Classification procedure

177 Supervised classification of the remotely-sensed data was carried out using the following 10

178 classification algorithms available in the R-based package Caret and implemented in the

179 RStoolbox package, version 0.1.5 (Kuhn, 2017; Leutner \& Horning, 2017): amdai (Adaptive

180 Mixture Discriminant Analysis), avNNet (Model Averaged Neural Network), gbm (Stochastic

181 Gradient Boosting), knn (k-Nearest Neighbours), mda (Mixture Discriminant Analysis), pls

182 (Partial Least Squares), rf (Random Forest), svmPoly (Support Vector Machines with

183 Polynomial Kernel), svmLinear (Support Vector Machines with Linear Kernel) and svmRadial

184 (Support Vector Machines with Radial Basis Function Kernel). In addition, two ensemble

185 procedures were performed: 1) a simple voting system ('Ens_SV'; the so-called 'majority

186 voting' and 'select all majority' system, sensu Bauer et al. 1999), considering each habitat map 
187 as an equally weighted vote; and 2) a weighted voting approach ('Ens_WV'), using overall

188 accuracy obtained by individual classifiers as weights (Du et al., 2012).

189

190

Eight habitat classes, defined as areas with common ecological and biophysical

191

characteristics and, therefore, with a homogeneous spectral signature, were identified in the

192

study area. For these habitat classes, we adopted the terminology used in the Annex I of the

193

Habitats Directive. These eight habitat classes correspond with 23 specific habitats listed in this

194

Annex I in our study area (Table 1). The study area is very well described, and the whole list of

195

habitats is already defined in previous reports (see e.g, Ramil-Rego et al., 2008). Training and

validation areas for each habitat class were established by on-screen digitizing in QGIS software,

and consisted of a set of pixels identified over well-known homogeneous areas in each Landsat

image, thus providing a reference spectral signature for each class. In particular, we applied a

stratified random design as sampling strategy, with a total of about 259-346 training and

200

validation areas proportionally distributed throughout the entire study area for each year (Table

201

2; Dataset S1). Specifically, for 2003 we used different Red-Green-Blue (RGB) composites from

202

the Landsat bands and digital orthophotos in natural colours at a scale of 1:18,000 obtained from

203

the Plan Nacional de Ortofotografía Aérea (PNOA) for 2004, while for 2016 we used digital

204 orthophotos from 2014.

205

206

\section{Validation procedure}

207 The accuracy of habitat maps was assessed from confusion matrices based on the number

208 of pixels correctly (and incorrectly) classified per class, and by comparing the results obtained

209 from different classification algorithms. The main quality parameters were the overall accuracy 
210 (\%), the producer's and user's accuracies, and the Kappa index of agreement. We used

211 McNemar's tests to evaluate statistical significance of the difference in accuracy between each

212 pair of algorithms. This is a non-parametric test that is based on confusion matrices collapsed to

2132 by 2 contingency tables (Foody, 2004; de Leeuw et al., 2006). P-values from McNemar's tests

214 were represented with heatmaps to help visualizing statistical significance of the difference

215 between all possible comparisons. These p-values were used to support the selection of

216 algorithms for the subsequent ensemble procedures. Thereby, classification algorithms with

217 statistically lower accuracies were not included in the ensemble procedures (McNemar's tests, $p$ $218<0.05)$

219

220 Data importation, pre-processing, spectral indices, image classification and graphical

221 display were performed using the toolset available in RStoolbox package, version 0.1.5

222 (Wegmann, Leutner \& Dech, 2016; Leutner \& Horning, 2017) (see

223 http://rpubs.com/ARegos/359655 for R code and formatted outputs).

224

225 Change analysis

226 We quantified the spatial extent (in ha) of each habitat class per year (2003 and 2016) from each

227 classification algorithm and ensemble approach. Boxplots were constructed using the R package 228 ggplot2 (Wickham, 2009). The contribution of each habitat class to the habitat change (i.e., 229 conversion from one habitat class to another) was showed through a transition matrix obtained 230 by cross-tabulation of the habitat maps derived from the two ensemble classification approaches.

231 Transition matrices were computed with the R package lulcc v.1.0.2 (Moulds, 2017) (see

232 http://rpubs.com/ARegos/359655 for R code and formatted outputs). 


\section{Results}

235 Accuracy assessment

236 The habitat maps with the highest accuracy (up to 95\%) in 2003 were obtained using support

237 vector machines and discriminant analysis, with the 'amdai' classifier providing slightly better

238 results (Fig. 2). For 2016, the highest accuracy was obtained by applying support vector

239 machines with linear kernel (Fig. 2). However, McNemar's test did not show statistical

240 significance of the difference in accuracy between individual classification algorithms $(\mathrm{p}>0.05$;

241 Fig. 3), except for 'pls', 'avNNet' (p < 0.01; Fig. 3), 'gbm and 'svmRadial' (p < 0.05; Fig. 3).

242 These algorithms showed limitations for specific habitat classes that have led to under- and

243 overestimations of their extent (Figs. 4). For instance, 'pls' showed very low user's accuracies

244 for the thematic class 'forest', while 'svmRadial' markedly overestimated the habitat class 'tidal

245 area' (see low user's accuracy and high producer's accuracy values, i.e. low omission errors and

246 high commission errors in Fig. 4). Thereby, 'pls' and 'avNNet' for both years and 'gbm' and

247 'svmRadial' for year 2016 were finally not considered during the ensemble procedures.

248

249

250

251

252 253 methods.
The habitat maps derived from the ensemble approaches (majority and weighted vote) showed an overall accuracy of $94 \%$ for the 2003 data (Kappa index of 0.93 ) and of $95 \%$ for the 2016 data (Kappa index of 0.94) (Fig. 2) with no statistical significance of the difference between them $(\mathrm{p}>0.05)$. Change analysis was therefore performed using the two ensemble 


\section{Change analysis}

256 The change analysis revealed important temporal dynamics between 2003 and 2016 for the

257 habitat classes identified in the study area (Fig 5, Table 3). However, the changes depended on

258 the classification algorithm used (Fig. 5). For example, values for water-dependent habitat

259 classes ranged from around 60 ha with most of the classification algorithms, to almost 7 times

260 this value with the 'svmRadial' classifier, clearly indicating overestimation of this unit (Figs. 5, 6

261 and 7). The coverage estimated for habitat class dominated by salt marshes and meadows in 2016

262 ranged from values close to 52 ha with the 'svmRadial' classifier to more than 260 ha with the

263 'gbm' classifier (Fig. 5).

264

265 The habitat maps obtained using the two ensemble classification approaches show a 266 reduction in habitat classes dominated by salt marshes and meadows (24.6-26.5\%), natural and 267 semi-natural grasslands (25.9-26.5\%) or sand dunes $(20.7-20.9 \%)$ and an increase in forest (31$26834 \%$ ) and reed bed (60.7-67.2\%) in the study area (Fig. 5). In particular, the spatial extent of

269 habitat classes characterized by salt marshes and meadows or natural and semi-natural grasslands

270 have largely changed in favour of those dominated by reed bed and forest (Table 3). Burned

271 areas were only identified in 2016, mainly affecting habitat classes with forest, salt marshes and

272 meadows and, to a lesser extent, natural and semi-natural grasslands (Table 3). Areas dominated 273 by 'sea dunes' remained almost unchanged (Fig 4, Table 3).

274

275 Discussion

276 Our results confirm the useful role that EO technologies may have in the reporting obligations

277 posed on the Member States by the European Habitats Directive, as well as in the cost-effective 
278 monitoring of natural habitats included in the Annex I. This should provide additional support to

279 local managers and decision-makers in relation to the implementation of medium- and long-term

280 conservation measures. However, the uncertainty arising from the large variety of classification

281 methods used may prevent local managers from basing their decisions on EO data. Our results

282 shed light on how different classification algorithms may provide very different quantitative

283 estimates, especially for water-dependent habitats (Fig. 5). In this respect, our findings confirm

284 the need to deal with this uncertainty by using ensemble classification approaches (Figs. 5, 6 and

285 7), to effectively improve the accuracy and stability of remote sensing image classification (for a

286 review, see Du et al., 2012). Despite these advantages, detailed habitat mapping may require

287 advanced EO technologies (e.g. hyperspatial, hyperspectral, LiDAR) to overcome several

288 constraints that limit the contribution of remote sensing to the reporting obligations of Habitats

289 Directive, such as the spectral similarity of the land covers that belong to different habitat types,

290 the spectral difference of the covers that belong to the same habitat type (Delalieux et al., 2010;

291 Borre et al., 2011) or their highly dynamic nature (Gallant, 2015).

292

Our findings showed important changes in the habitat classes over the last 13 years (Fig.

5, Table 3), with potential impacts on natural habitats included in the Habitats Directive (Table

1). The habitat class dominated by salt marshes and meadows has decreased by as much as $25 \%$

marshes and meadows habitats include Salicornia species and other annuals colonizing mud and sand (habitat code 1310), Atlantic salt meadows (Glauco-Puccinellietalia maritimae) (habitat code 1330) and Mediterranean and thermo-Atlantic halophilous scrubs (Sarcocornetea fruticosi)

300 (habitat code 1420). This habitat class has been negatively affected by wildfires, forest expansion 
301 and, to a lesser extent, conversion of the land to natural and semi-natural grasslands (see

302 transitions in Table 3). These patterns can be explained by the concomitant effects of

303 abandonment of traditional agropastoral practices, which may indirectly promote forest spread

304 and expansion (Stellmes et al., 2013; Regos et al., 2015), a high-frequency fire regime (Chas-

305 Amil, 2007) and land-use changes caused by agricultural conversion, as reported for other

306 protected wetlands in southern Spain (Zorrilla-Miras et al., 2014).

307

Natural and semi-natural grasslands have undergone the greatest decline (of up to $26 \%$ ) since designation of the site as part of the Natura 2000 network. This habitat class includes Molinia meadows (habitat code 6410), humid grasslands of the Molinio-Holoschoenion (habitat code 6420), hydrophilous tall herb fringe communities (habitat code 6430) and hay meadows (Alopecurus pratensis, Sanguisorba officinalis) (habitat code 6510). Natural and semi-natural

313 grasslands were mainly replaced by coniferous forest and to a lesser extent by 'sea dune' habitats 314 (Table 3), also indicating afforestation as a main threat. These grasslands were also slightly affected by wildfire in 2016. However, the loss and degradation of these habitats was also related 316 to the gradual expansion of invasive species (Gonzalez-Martínez, 2014; González-Martínez, 317 2017). In this respect, new advances in remote sensing technologies and the availability of new

318 sensors with higher temporal, spectral and spatial resolution such as Sentinel-2 from the 319 European Space Agency (ESA) and low-cost unmanned aerial vehicles (UAVs, also known as 320 drones) should contribute greatly to monitoring of invasive species (Lehmann et al., 2017; Ng et 321 al., 2017), and to better delineation and mapping of the habitats under EU protection (Adam,

322 Mutanga \& Rugege, 2010; Marcaccio, Markle \& Chow-Fraser, 2015; Stratoulias et al., 2015;

323 Gonçalves et al., 2016). 
The area covered by habitat classes dominated by sandbanks, sandflats and shifting dunes

326 ('white and mobile dunes') (see habitat codes in Table 1) decreased by more than $20 \%$ relative to

327 the cover in 2003 (Fig. 5), in favour of vegetated dunes ('sea dunes') (Table 3). Sandbanks, mud

328 flats and sandflats are strongly affected by coastal dynamics in the long term and by intertidal

329 fluctuations in the short term. Such dynamics may also have contributed to horizontal

330 displacement of the main 'white dune' (66.5 $\mathrm{m}$ in the last decade, see Appendix S1). Despite the

331 losses and gains estimated for 'sea dunes' over the last 13 years, this habitat class (which

332 includes three priority habitats, see description in Table 1) was found to be the most stable over

333 time (Fig. 5, Table 3). This stability has also important conservation implications for other

334 species listed in the European Directives. For instance, 'grey dune' is the breeding habitat for the 335 Eurasian Stone Curlew (Burhinus oedicnemus) (Domínguez, Otero \& Vidal, 2006), which is 336 included in Annex I of the Birds Directive, and in the Galician Catalogue of Threatened Species.

Reed bed, mainly represented by Phragmites australis, has increased greatly since

339 designation of the site as part of the Natura 2000 network (Fig. 5, Table 3). This increase may

340 have been directly favoured by protection of the site and the gradual decline in the traditional

341 reed management (harvesting and burning) by local communities (Valkama, Lyytinen \&

342 Koricheva, 2008). Although Phragmites australis reed bed is not listed in the Habitats Directive,

343 the plant is included in several habitat types of the Annex I, such as estuaries (habitat code

344 1130), coastal lagoons (habitat code 1150) and inland salt marsh (habitat code 1340) (Romão,

345 1996). Moreover, changes affecting reed bed may also have subsequent effects on other species

346 associated with these habitats (Valkama, Lyytinen \& Koricheva, 2008), such as the Reed 
347 Bunting (Emberiza schoeniclus lusitanica) (Kvist et al., 2011; BirdLife International, 2017a) and

348 the Common Little Bittern (Ixobrychus minutus) (BirdLife International, 2017b), both included

349 in the Annex I of the Birds Directive and the Spanish and Galician Catalogue of Threatened

350 Species. Therefore, its management and conservation may also have positive effects on species

351 protected by the Birds Directive.

352

353 Conclusions

354 Earth observation (EO) technologies may provide cost-effective means of medium- and long-

355 term monitoring of wetland habitats. The proposed methodology is useful for relatively

356 inaccessible sites (e.g. coastal lagoons or reed beds) as it only requires ecological rules based on

357 expert knowledge. Habitat changes can be detected by comparing pairs of maps, and trends can

358 be quantified. This study therefore illustrates how EO-based approaches might be particularly

359 useful to help (1) managers to monitor their decisions in relation to conservation, (2) Member

360 States to comply with the requirements of the European Habitats Directive (92/43/EEC), and (3)

361 the European Commission to monitor the conservation status of natural habitat types of

362 community interest included in Annex I of the Habitats Directive.

363

364 References

365 Adam E., Mutanga O., Rugege D. 2010. Multispectral and hyperspectral remote sensing for

366 identification and mapping of wetland vegetation: A review. Wetlands Ecology and

367 Management 18:281-296. DOI: 10.1007/s11273-009-9169-z.

368 Adamo M., Tarantino C., Tomaselli V., Veronico G., Nagendra H., Blonda P. 2016. Habitat

369 mapping of coastal wetlands using expert knowledge and Earth observation data. Journal of 

Applied Ecology 53:1521-1532. DOI: 10.1111/1365-2664.12695.

371 Alcaraz-Segura D., Cabello J., Paruelo JM., Delibes M. 2009. Use of descriptors of ecosystem 372 functioning for monitoring a national park network: A remote sensing approach. Environmental Management 43:38-48. DOI: 10.1007/s00267-008-9154-y.

374 Bauer E., Kohavi R., Chan P., Stolfo S., Wolpert D. 1999. An Empirical Comparison of Voting 375 Classification Algorithms: Bagging, Boosting, and Variants. Machine Learning 36:105376 139. DOI: $10.1023 / \mathrm{a}: 1007515423169$.

377 378

379 380

381

382

383

384

385

386

387

388

389

390

391

392

BirdLife International. 2017a.Species factsheet: Emberiza schoeniclus. Downloaded from http://www.birdlife.org on 20/12/2017.

BirdLife International. 2017b.Species factsheet: Ixobrychus minutus. Downloaded from http://www.birdlife.org on 20/12/2017

Borre J Vanden., Haest B., Lang S., Spanhove T., Förster M., Sifakis NI. 2011. Towards a wider uptake of remote sensing in Natura 2000 monitoring: Streamlining remote sensing products with users' needs and expectations. In: 2nd International Conference on Space Technology, ICST 2011. DOI: 10.1109/ICSpT.2011.6064686.

Briem GJ., Benediktsson JA., Sveinsson JR. 2002. Multiple classifiers applied to multisource remote sensing data. IEEE Transactions on Geoscience and Remote Sensing 40:2291-2299. DOI: $10.1109 /$ TGRS.2002.802476.

Chas-Amil ML. 2007. Forest fires in Galicia (Spain): Threats and challenges for the future. Journal of Forest Economics 13:1-5. DOI: 10.1016/j.jfe.2007.02.001.

Cracknell MJ., Reading AM. 2014. Geological mapping using remote sensing data: A comparison of five machine learning algorithms, their response to variations in the spatial distribution of training data and the use of explicit spatial information. Computers and 
Geosciences 63:22-33. DOI: 10.1016/j.cageo.2013.10.008.

394 Davidson NC. 2014. How much wetland has the world lost? Long-term and recent trends in 395 global wetland area. Marine and Freshwater Research 65:934-941. DOI:

$396 \quad 10.1071 / \mathrm{MF} 14173$.

397 Delalieux S., Somers B., Haest B., Kooistra L., Mücher CA., Vanden Borre J. 2010. Monitoring 398 heathland habitat status using hyperspectral image classification and unmixing. In: $2 n d$ 399 Workshop on Hyperspectral Image and Signal Processing: Evolution in Remote Sensing, WHISPERS 2010 - Workshop Program. 7-10. DOI: 10.1109/WHISPERS.2010.5594895.

401

402

403

404

405 406

407 408

409

410

411

412

413

414 Gonçalves J., Henriques R., Alves P., Sousa-Silva R., Monteiro AT., Lomba Â., Marcos B., 415

Domínguez J., Otero M., Vidal M. 2006. Guía de las aves del Parque Natural do complexo dunar de Corrubedo e lagoas de Carregal e Vixán. Santiago de Compostela, Consellería de Medio Ambiente e Desenvolvemento Sostible. Santiago de Compostela.

Du P., Xia J., Zhang W., Tan K., Liu Y., Liu S. 2012. Multiple classifier system for remote sensing image classification: A review. Sensors 12:4764-4792. DOI: 10.3390/s120404764.

Foody GM. 2004. Thematic map comparison: evaluating the statistical significance of differences in classification accuracy. Photogrammetric Engineering \& Remote Sensing 70:627-633. DOI: 0099-1112/04/7005-0627/\$3.00/0.

Gallant AL. 2015. The challenges of remote monitoring of wetlands. Remote Sensing 7:1093810950. DOI: $10.3390 /$ rs70810938.

Gao BC. 1996. NDWI - A normalized difference water index for remote sensing of vegetation liquid water from space. Remote Sensing of Environment 58:257-266. DOI: 10.1016/S0034-4257(96)00067-3. Honrado J. 2016. Evaluating an unmanned aerial vehicle-based approach for assessing 
416 habitat extent and condition in fine-scale early successional mountain mosaics. Applied 417 Vegetation Science 19:132-146. DOI: 10.1111/avsc.12204.

418 Gonzalez-Martínez XI. 2014. Nuevos datos sobre xenoflora en el término municipal de Ribeira 419 (A Coruñ). Nova Acta Cientifica Compostelana 21:65-76.

420 González-Martínez XI. 2017. Contribución al conocimiento de la flora alóctona de Galicia (NO

421 Península Ibérica, España). Botanica Complutense 41:53-67.

422 De Groot R., Stuip M., Finlayson M., Davidson N. 2006. Valuing wetlands: guidance for valuing 423 the benefits derived from wetland ecosystem services. International Water Management $424 \quad$ Institute.

425 Horwitz P., Finlayson CM. 2011. Wetlands as Settings for Human Health: Incorporating 426 Ecosystem Services and Health Impact Assessment into Water Resource Management. 427 BioScience 61:678-688. DOI: 10.1525/bio.2011.61.9.6.

428 Hubert-Moy L., Cotonnec A., Le Du L., Chardin A., Perez P. 2001. A comparison of parametric 429 classification procedures of remotely sensed data applied on different landscape units. Remote Sensing of Environment 75:174-187. DOI: 10.1016/S0034-4257(00)00165-6.

431 Khatami R., Mountrakis G., Stehman S. 2016. A meta-analysis of remote sensing research on 432 supervised pixel-based land-cover image classification processes: General guidelines for 433 practitioners and future research. Remote Sensing of Environment 177:89-100. DOI: 10.1016/j.rse.2016.02.028.

Kuhn M. 2017. caret: Classification and Regression Training. R package version 6.0-76. https://CRAN.R-project.org/package=caret.

437 Kvist L., Ponnikas S., Belda EJ., Encabo I., Martínez E., Onrubia A., Hernández JM., Vera P., 438 Neto JM., Monrós JS. 2011. Endangered subspecies of the Reed Bunting (Emberiza 
439

440

441

442

443

444

445

446

447

448

449

450

451

452

453

454

455

456

457

458

459

460

461

schoeniclus witherbyi and E. s. lusitanica) in Iberian Peninsula have different genetic structures. Journal of Ornithology 152:681-693. DOI: 10.1007/s10336-011-0646-9.

de Leeuw J., Jia H., Yang L., Liu X., Schmidt K., Skidmore AK. 2006. Comparing accuracy assessments to infer superiority of image classification methods. International Journal of Remote Sensing 27:223-232. DOI: 10.1080/01431160500275762.

Lehmann JRK., Prinz T., Ziller SR., Thiele J., Heringer G., Meira-Neto JAA., Buttschardt TK. 2017. Open-Source Processing and Analysis of Aerial Imagery Acquired with a Low-Cost Unmanned Aerial System to Support Invasive Plant Management. Frontiers in Environmental Science 5:1-16. DOI: 10.3389/fenvs.2017.00044.

Leutner B., Horning N. 2017. RStoolbox: Tools for Remote Sensing Data Analysis. R package version 0.1.8. https://CRAN.R-project.org/package=RStoolbox.

Leyequien E., Verrelst J., Slot M., Schaepman-Strub G., Heitkönig IMA., Skidmore A. 2007. Capturing the fugitive: Applying remote sensing to terrestrial animal distribution and diversity. International Journal of Applied Earth Observation and Geoinformation 9:1-20. DOI: 10.1016/j.jag.2006.08.002.

Lu D., Weng Q. 2007. A survey of image classification methods and techniques for improving classification performance. International Journal of Remote Sensing 28:823-870. DOI: $10.1080 / 01431160600746456$.

Marcaccio J V., Markle CE., Chow-Fraser P. 2015. Unmanned aerial vehicles produce highresolution, seasonally-relevant imagery for classifying wetland vegetation. International Archives of the Photogrammetry, Remote Sensing and Spatial Information Sciences 40:249256. DOI: 10.5194/isprsarchives-XL-1-W4-249-2015.

Moulds S. 2017. lulcc: Land Use Change Modelling in R. R package version 1.0.2. https://cran.r- 
462 project.org/package=lulcc.

463 Muchoney DM. 2008. Earth observations for terrestrial biodiversity and ecosystems. Remote

464 Sensing of Environment 112:1909-1911. DOI: 10.1016/j.rse.2008.01.003.

465 Ng WT., Rima P., Einzmann K., Immitzer M., Atzberger C., Eckert S. 2017. Assessing the

466 potential of sentinel-2 and pléiades data for the detection of prosopis and vachellia spp. in

467 Kenya. Remote Sensing 9. DOI: 10.3390/rs9010074.

468 O’Connor B., Secades C., Penner J., Sonnenschein R., Skidmore A., Burgess ND., Hutton JM.

469 2015. Earth observation as a tool for tracking progress towards the Aichi Biodiversity

470 Targets. Remote Sensing in Ecology and Conservation 1:19-28. DOI: 10.1002/rse2.4.

471 Petrou ZI., Manakos I., Stathaki T. 2015. Remote sensing for biodiversity monitoring: a review

472 of methods for biodiversity indicator extraction and assessment of progress towards

473 international targets. Biodiversity and Conservation 24:2333-2363. DOI: 10.1007/s10531-

$474 \quad$ 015-0947-z.

475 Ramil-Rego P. 2007. Evaluación del estado de conservación de las lagunas costeras de Galicia:

476 Propuestas de conservación y uso sostenible. Fundación Arao. Santiago de Compostela.

477 Ramil-Rego P., Rodríguez-Guitián MA., Ferreiro da Costa J., Rubinos-Román M., Gómez-

478 Orellana Rodríguez L., de Nóvoa Fernández B., Hinojo-Sánchez BA., Martínez-Sánchez S.,

479 Cillero-Castro C., Alberto Díaz-Varela R., Rodríguez-González PM., Muñoz-Sobrino C.

480 2008. Os Hábitats de Interese Comunitario en Galicia. Fichas descritivas. Monografías do

481 Ibader. Universidade de Santiago de Compostela. Lugo.

482 Regos A., Ninyerola M., Moré G., Pons X. 2015. Linking land cover dynamics with driving

483 forces in mountain landscape of the Northwestern Iberian Peninsula. International Journal

484 of Applied Earth Observation and Geoinformation 38:1-14. DOI: 
486

487

488

489

490

491

492

493

494

495

496

497

498

499

500

501

502

503

504

505

506

507

Romão C. 1996. Interpretation manual of European Union habitats. Version EUR 15. European Commission, Brussels.

Skidmore AK., Pettorelli N., Coops NC., Geller GN., Hansen M., Lucas R., Mücher CA., O’Connor B., Paganini M., Pereira HM., Schaepman ME., Turner W., Wang T., Wegmann M. 2015. Environmental science: Agree on biodiversity metrics to track from space. Nature 523:403-405. DOI: 10.1038/523403a.

Stellmes M., Röder A., Udelhoven T., Hill J. 2013. Mapping syndromes of land change in Spain with remote sensing time series, demographic and climatic data. Land Use Policy 30:685702. DOI: 10.1016/j.landusepol.2012.05.007.

Stratoulias D., Balzter H., Sykioti O., Zlinszky A., Tóth VR. 2015. Evaluating sentinel-2 for lakeshore habitat mapping based on airborne hyperspectral data. Sensors 15:22956-22969. DOI: $10.3390 / \mathrm{s} 150922956$.

Thorsell J., Levy R., Sigaty T. 1997. A Global Overview of Wetland and Marine Protected Areas on the World Heritage List: A Contribution to the Global Theme Study of World Heritage Natural Sites.

Turner W., Rondinini C., Pettorelli N., Mora B., Leidner A., Szantoi Z., Buchanan G., Dech S., Dwyer J., Herold M., Koh LP., Leimgruber P., Taubenboeck H., Wegmann M., Wikelski M., Woodcock C. 2015. Free and open-access satellite data are key to biodiversity conservation. Biological Conservation 182:173-176. DOI: 10.1016/j.biocon.2014.11.048.

Valkama E., Lyytinen S., Koricheva J. 2008. The impact of reed management on wildlife: A meta-analytical review of European studies. Biological Conservation 141:364-374. DOI: 10.1016/j.biocon.2007.11.006. 
508 Vázquez-Paz M., Pérez-Alberti A. 2002. Análisis dinámico y medioambiental de un espacio 509 protegido en la costa atlántica gallega (Parque Natural de Corrubedo, A Coruña). $510 \quad$ Xeográfica 2:155-176.

511 Wegmann M., Leutner B., Dech S. 2016. Remote sensing and GIS for ecologists: using open 512 source software. Pelagic Publishing Ltd, Exeter.: Pelagic Publishing Ltd.

513 Wickham. 2009. ggplot2: Elegant Graphics for Data Analysis. Springer-Verlag New York. 514 Zorrilla-Miras P., Palomo I., Gómez-Baggethun E., Martín-López B., Lomas PL., Montes C.

515 2014. Effects of land-use change on wetland ecosystem services: A case study in the

516 Doñana marshes (SW Spain). Landscape and Urban Planning 122:160-174. DOI:

$517 \quad$ 10.1016/j.landurbplan.2013.09.013.

518 


\section{Table $\mathbf{1}$ (on next page)}

List of broad habitat classes used in the change analysis and their correspondence with the natural habitats (and codes) listed in the Annex I of the Habitats Directive.

Asterisk indicates habitats with highest priority for conservation according to the Habitats Directive. 
1110 Sandbanks which are slightly covered by sea water all the time.

1140 Mud flats and sandflats not covered by sea water at low

Sand dunes tide.

1210 Annual vegetation of drift lines.

2110 Embryonic shifting dunes.

2120 Shifting dunes along the shoreline with Ammophila arenaria ('white dunes').

1130 Estuaries.

Tidal areas

1150* Coastal lagoons.

1160 Large shallow inlets and bays.

1170 Reefs.

\section{Forest \\ Reedbed}

Sea dunes of Atlantic coast

\section{$2130 *$ Fixed coastal dunes with herbaceous vegetation ('grey} dunes')

2150* Atlantic decalcified fixed dunes (Calluno-Ulicetea). 2190 Humid dune slacks.

2230 Malcolmietalia dune grasslands.

2260 Cisto-Lavenduletalia dune sclerophyllous scrubs. 6220* Pseudo-steppe with grasses and annuals of the TheroBrachypodietea

6410 Molinia meadows on calcareous, peaty or clayey-siltladen soils (Molinion caeruleae).

Natural and seminatural grasslands

6420 Mediterranean tall humid grasslands of the MolinioHoloschoenion.

6430 Hydrophilous tall herb fringe communities of plains and of the montane to alpine levels.

6510 Lowland hay meadows (Alopecurus pratensis, Sanguisorba officinalis)

1310 Salicornia and other annuals colonizing mud and sand.

Salt marshes and meadows
1330 Atlantic salt meadows (Glauco-Puccinellietalia maritimae).

1420 Mediterranean and thermo-Atlantic halophilous scrubs (Sarcocornetea fruticosi).

\section{Burned areas}




\section{Table 2 (on next page)}

Total number of training and validation areas considered in the supervised classification for each habitat class and year. 
1
2
3
4

\begin{tabular}{|l|c|c|c|c|}
\hline \multicolumn{1}{|c|}{ Habitat class } & \multicolumn{2}{c|}{ Training } \\
\hline & \multicolumn{2}{|c|}{ Validation } & Training & \multicolumn{2}{|c|}{ Validation } \\
\hline Sand dunes & 38 & 30 & 35 & 29 \\
\hline Tidal areas & 48 & 29 & 49 & 31 \\
\hline Forest & 64 & 61 & 76 & 43 \\
\hline Reedbed & 21 & 22 & 20 & 23 \\
\hline $\begin{array}{l}\text { Sea dunes of Atlantic } \\
\text { coast }\end{array}$ & 46 & 29 & 56 & 29 \\
\hline $\begin{array}{l}\text { Natural and semi- } \\
\text { natural grasslands }\end{array}$ & 31 & 55 & 44 & 39 \\
\hline $\begin{array}{l}\text { Salt marshes and } \\
\text { meadows }\end{array}$ & 34 & 33 & 33 & 26 \\
\hline Burned areas & 0 & 0 & 39 & 23 \\
\hline TOTAL & 282 & 259 & 346 & 243 \\
\hline
\end{tabular}




\section{Table 3(on next page)}

Transition matrices obtained from the simply voting ('Ens_SV') and weighed voting ensemble ('Ens_WV') procedures from 2003 (rows) to 2016 (columns) (expressed in hectares) for the study area.

Habitat classes description can be found in Table 1. 
1

\begin{tabular}{|l|c|c|c|c|c|c|c|c|}
\hline Ens_SV & $\begin{array}{c}\text { Sand } \\
\text { dunes }\end{array}$ & $\begin{array}{c}\text { Burned } \\
\text { areas }\end{array}$ & $\begin{array}{c}\text { Tidal } \\
\text { areas }\end{array}$ & Forest & Reedbed & $\begin{array}{c}\text { Sea } \\
\text { dunes }\end{array}$ & Grasslands & $\begin{array}{c}\text { Salt } \\
\text { marshes }\end{array}$ \\
\hline Sand dunes & 53.64 & 0 & 8.01 & 0 & 0 & 18.27 & 0 & 0 \\
\hline $\begin{array}{l}\text { Burned } \\
\text { areas }\end{array}$ & 0 & 0 & 0 & 0 & 0 & 0 & 0 & 0 \\
\hline Tidal areas & 2.97 & 0 & 50.4 & 0 & 0 & 0.72 & 0 & 2.07 \\
\hline Forest & 0 & 9.45 & 0 & 128.7 & 1.08 & 0.9 & 9.81 & 2.97 \\
\hline Reedbed & 0.27 & 0.36 & 0 & 1.62 & 7.2 & 2.52 & 4.05 & 1.62 \\
\hline Sea dunes & 6.3 & 4.23 & 2.16 & 4.14 & 2.7 & 249.03 & 7.56 & 9.27 \\
\hline Grasslands & 0 & 6.93 & 0 & 38.43 & 9.36 & 30.78 & 147.51 & 3.15 \\
\hline Salt & 0 & 8.55 & 1.35 & 27.9 & 8.01 & 5.58 & 6.12 & 98.64 \\
\hline marshes & & & & & & & & \\
\hline Ens_WV & & & & & & & & \\
\hline Sand dunes & 54.54 & 0 & 7.92 & 0 & 0 & 18.36 & 0 & 0 \\
\hline Burned & 0 & 0 & 0 & 0 & 0 & 0 & 0 & 0 \\
\hline areas & & & & & & & & \\
\hline Tidal areas & 2.97 & 0 & 50.31 & 0 & 0 & 0.63 & 0 & 1.89 \\
\hline Forest & 0 & 9.36 & 0 & 128.79 & 1.08 & 0.81 & 9.09 & 2.88 \\
\hline Reedbed & 0.18 & 0.36 & 0 & 2.07 & 7.38 & 2.61 & 4.32 & 1.17 \\
\hline Sea dunes & 6.39 & 4.41 & 1.53 & 3.96 & 3.06 & 248.76 & 6.57 & 7.74 \\
\hline Grasslands & 0 & 6.93 & 0 & 40.5 & 10.71 & 32.31 & 147.69 & 2.7 \\
\hline $\begin{array}{l}\text { Salt } \\
\text { marshes }\end{array}$ & 0 & 8.37 & 1.44 & 28.62 & 8.01 & 5.85 & 4.95 & 97.11 \\
\hline & & & & & & & & \\
\hline
\end{tabular}


Figure 1

Location of the study area and protected-area systems

Ramsar wetland (dashed-dotted line), Natural park and SAC (black dashed line) and SPA (filling lines).

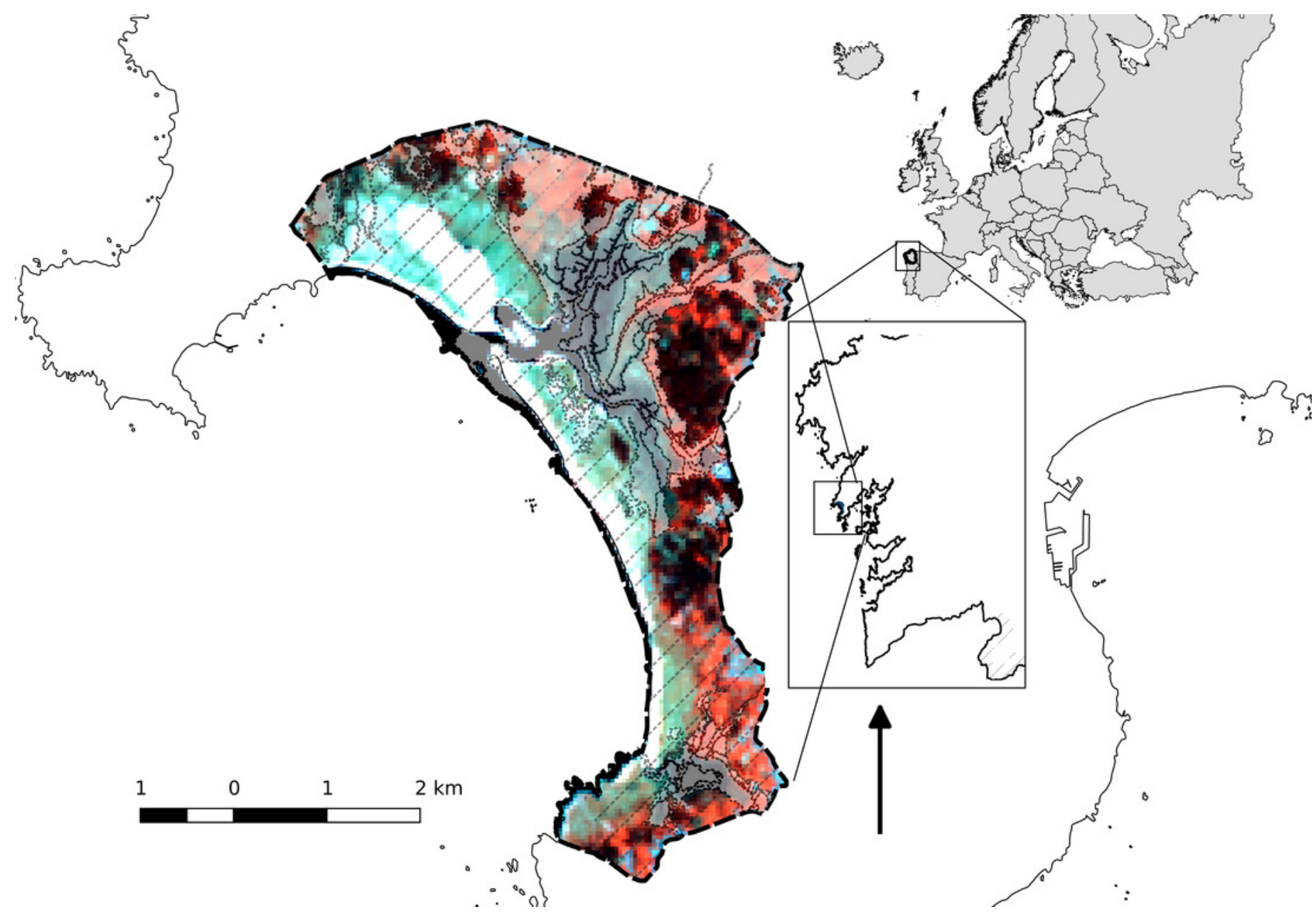




\section{Figure 2 (on next page)}

Accuracy of habitat maps (overall accuracy and Kappa coefficient) per year and classification method.

amdai (Adaptive Mixture Discriminant Analysis), avNNet (Model Averaged Neural Network), gbm (Stochastic Gradient Boosting), knn (k-Nearest Neighbours), mda (Mixture Discriminant Analysis), pls (Partial Least Squares), rf (Random Forest), svmPoly (Support Vector Machines with Polynomial Kernel), svmRadial (Support Vector Machines with Radial Basis Function Kernel), svmLinear (Support Vector Machines with Linear Kernel), simply voting ('Ens_SV') and weighted voting ('Ens_WV') ensemble approaches. The boxplots display the median, the $50 \%$ (box) and $95 \%$ (whiskers) confidence intervals. 
PeerJ

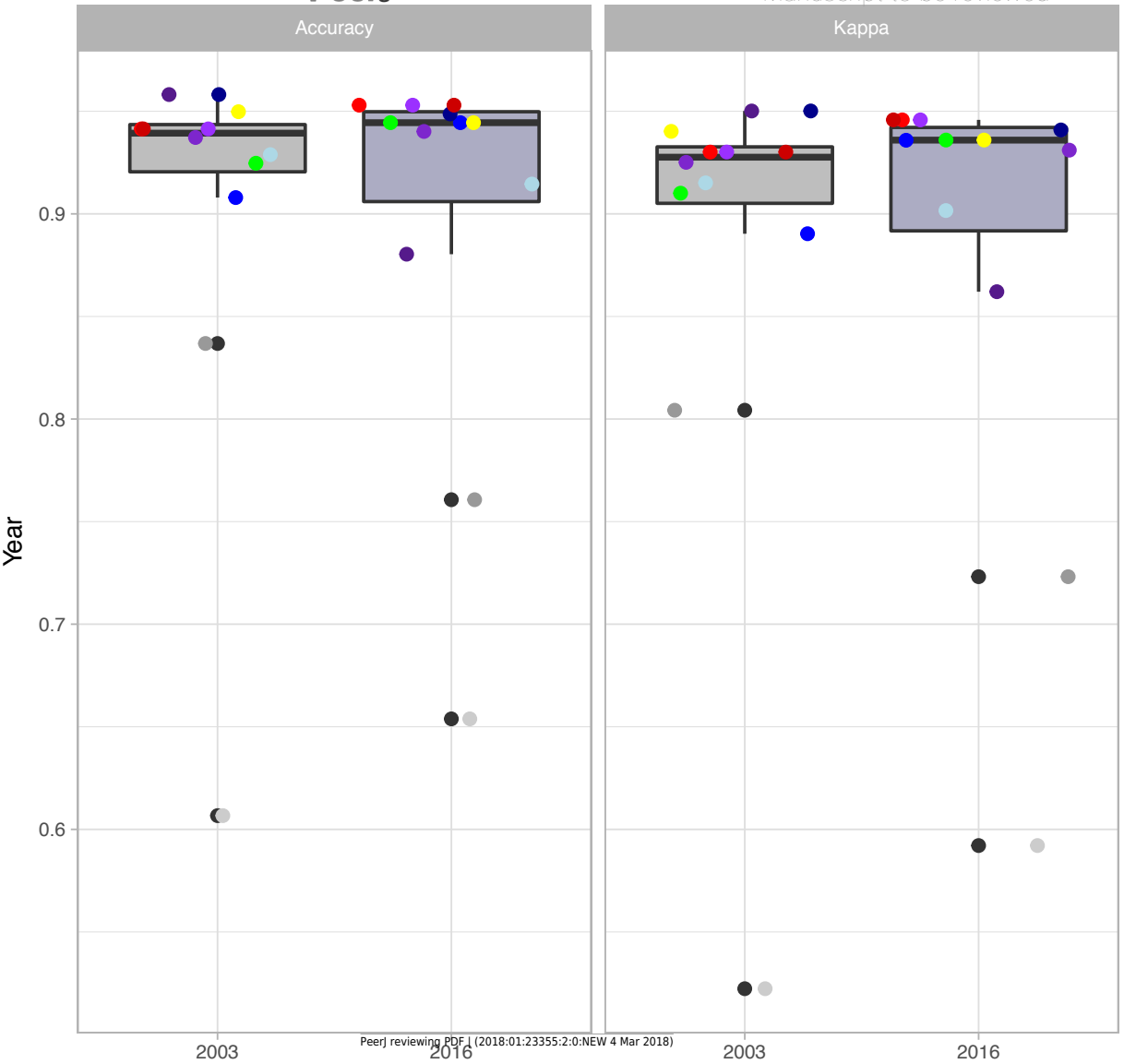

alg

amdai

avNNet

- Ens_SV

- Ens_WV

gbm

- knn

- mda

- pls

- if

- svmLinear

- svmPoly

- svmRadial

year

2003

2016 


\section{Figure 3 (on next page)}

P-value from McNemar's tests for each pair of classification algorithm.

amdai (Adaptive Mixture Discriminant Analysis), avNNet (Model Averaged Neural Network), gbm (Stochastic Gradient Boosting), knn (k-Nearest Neighbours), mda (Mixture Discriminant Analysis), pls (Partial Least Squares), if (Random Forest), svmPoly (Support Vector Machines with Polynomial Kernel), svmRadial (Support Vector Machines with Radial Basis Function Kernel), svmLinear (Support Vector Machines with Linear Kernel). White colours indicate pvalues lower than 0.01 , blue colour intensity increases with the $p$-value. 
A) Year 2003

PeerJ

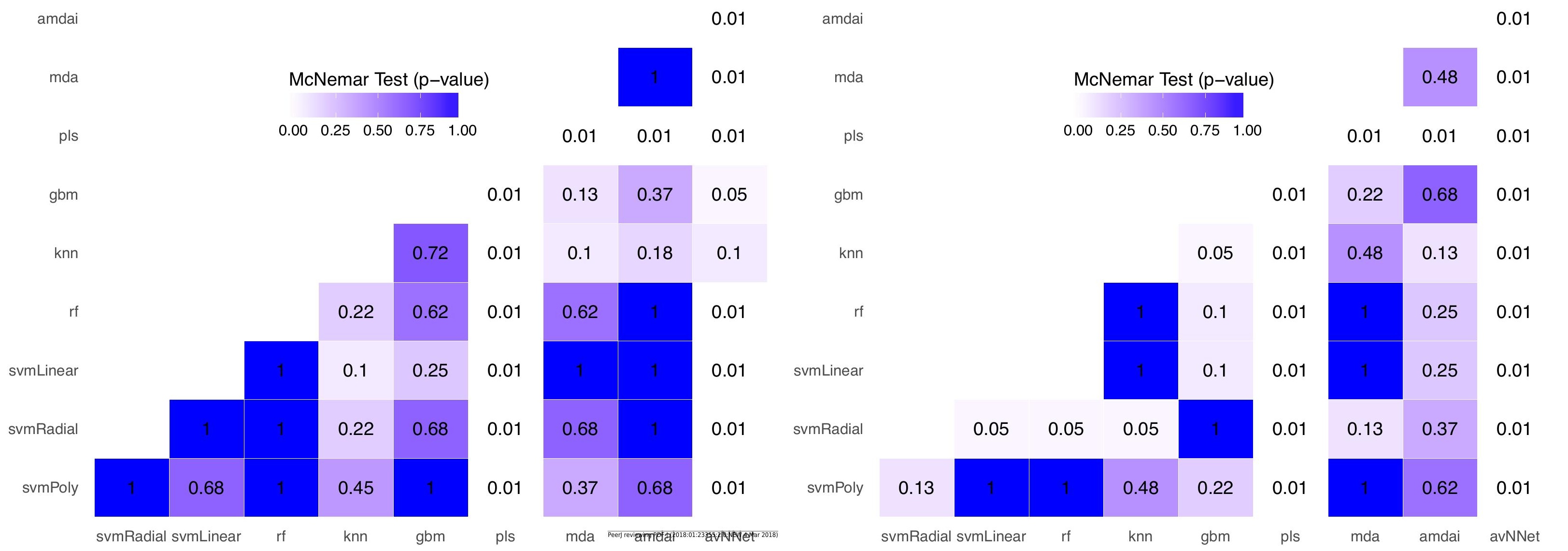


Figure 4 (on next page)

Producer's (PrA) and user's (UrA) accuracy per year, habitat class and classification method.

amdai (Adaptive Mixture Discriminant Analysis), avNNet (Model Averaged Neural Network), gbm (Stochastic Gradient Boosting), knn (k-Nearest Neighbours), mda (Mixture Discriminant Analysis), pls (Partial Least Squares), rf (Random Forest), svmPoly (Support Vector Machines with Polynomial Kernel), svmRadial (Support Vector Machines with Radial Basis Function Kernel), svmLinear (Support Vector Machines with Linear Kernel), simply voting ('Ens_SV') and weighted voting ('Ens_WV') ensemble approaches. See Table 1 for habitat classes. 


\section{PeerJ}
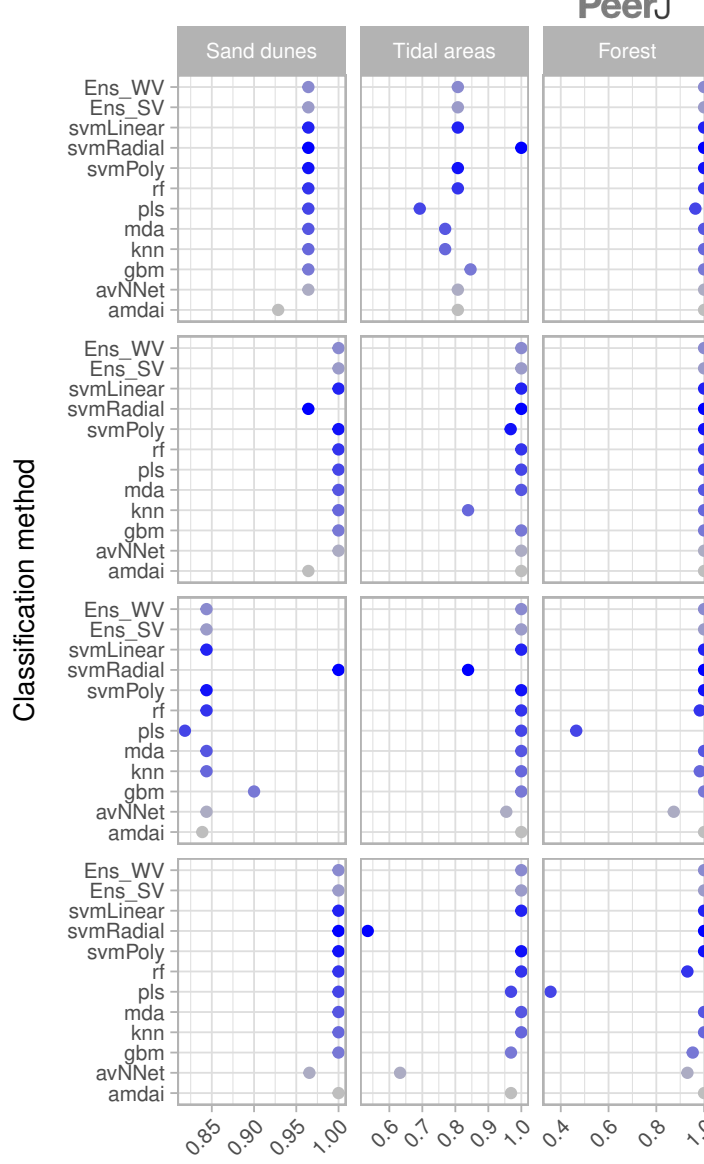
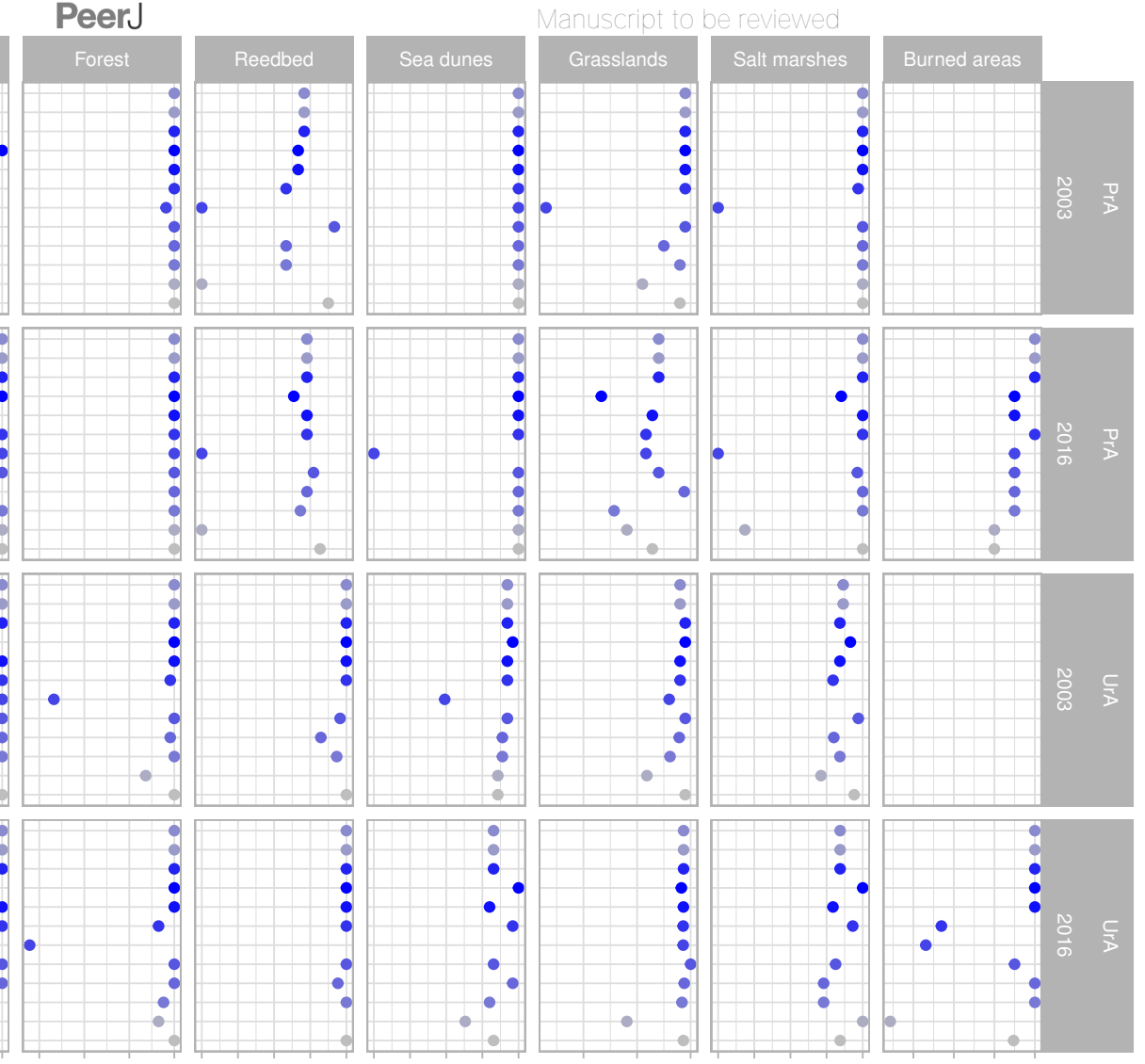

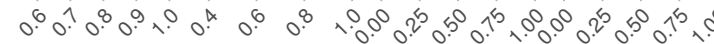

$\overline{\left.\text { Peer) reviewing PDF | (2018:01:233 ACCCErraley }{ }^{018}\right)}$

alg

- amdai

- avNNet

- Ens_SV

- Ens_WV

gbm

- knn

- mda

- pls

- $\quad$ if

- svmLinear

- svmPoly

- svmRadial 


\section{Figure 5(on next page)}

Extent (in ha) of each habitat class per year and classification algorithm ('alg').

The boxplots display the median, the $50 \%$ (box) and 95\% (whiskers) confidence intervals. See acronyms in Fig. 2. 



\section{Figure 6 (on next page)}

Habitat maps for 2003 obtained from each classification method.

amdai (Adaptive Mixture Discriminant Analysis), avNNet (Model Averaged Neural Network), gbm (Stochastic Gradient Boosting), knn (k-Nearest Neighbours), mda (Mixture Discriminant Analysis), pls (Partial Least Squares), rf (Random Forest), svmPoly (Support Vector Machines with Polynomial Kernel), svmRadial (Support Vector Machines with Radial Basis Function Kernel), svmLinear (Support Vector Machines with Linear Kernel), simply voting ('Ens_SV') and weighted voting ('Ens_WV') ensemble approaches. 
$4714000-$
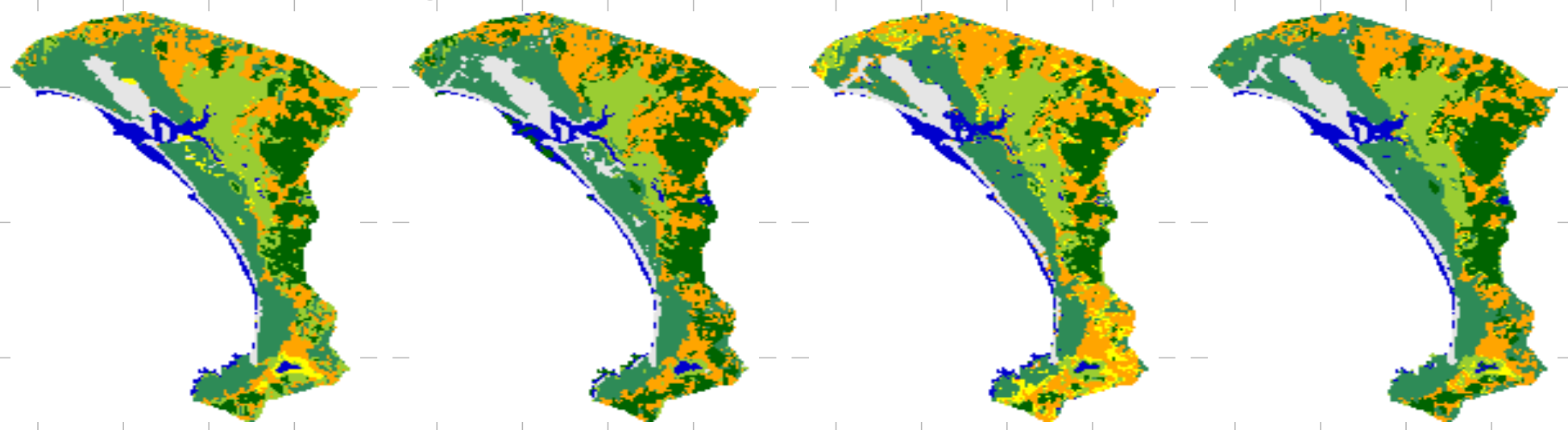

mda

\begin{tabular}{|l|l|}
\hline pls \\
\hline
\end{tabular}
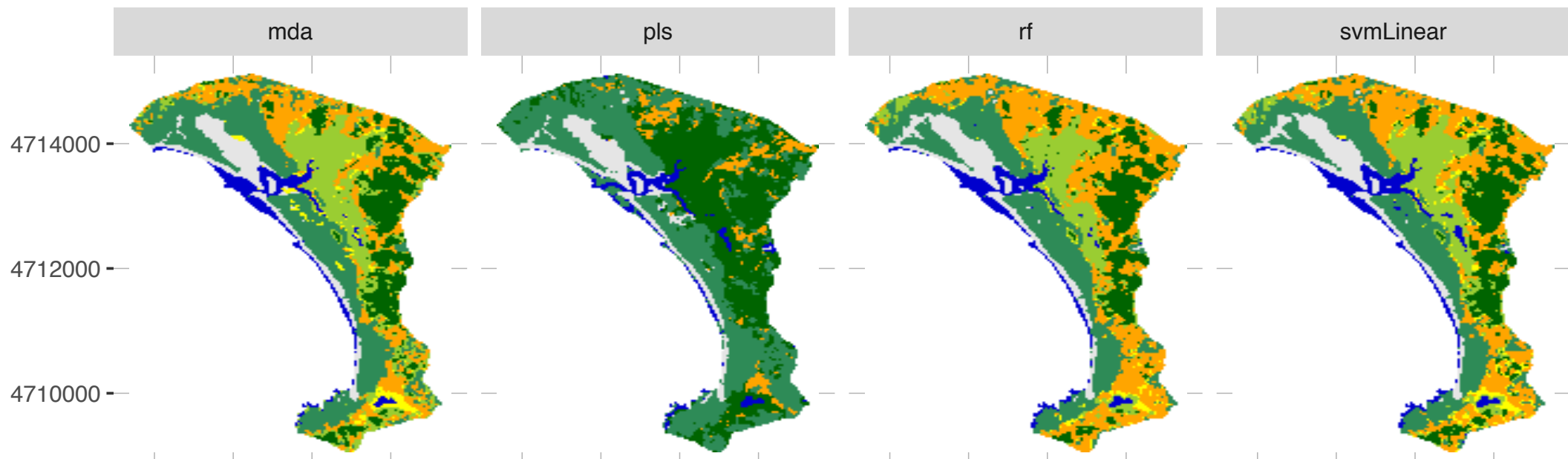

Habitats 2003

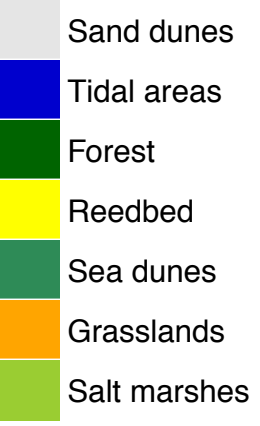

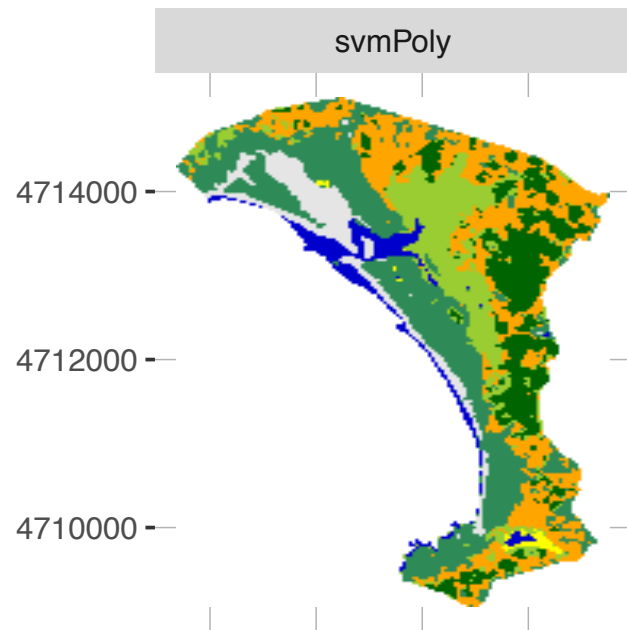

$495^{\prime} 0004966^{\prime} 000497^{\prime} 000498^{\prime} 000$

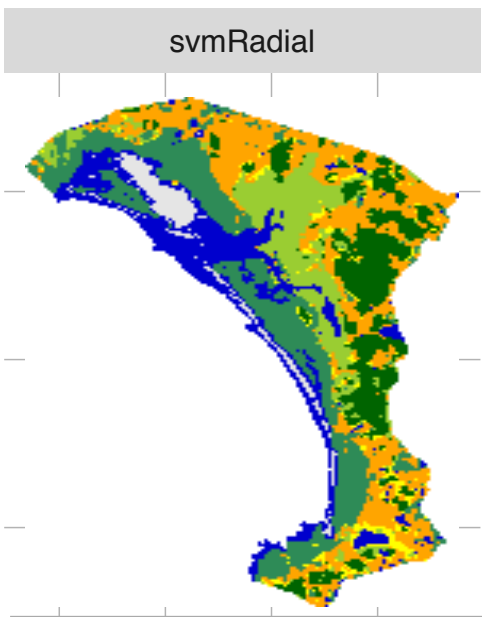

Peer)|reviewing PDF | (2018:01:23355:2; 0:NEW 4 Mar 2018) 495000496000497000498000

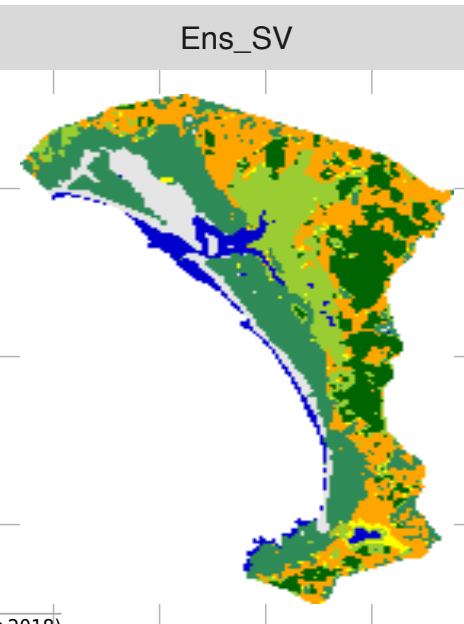

$495000496000497^{\prime} 000498000$

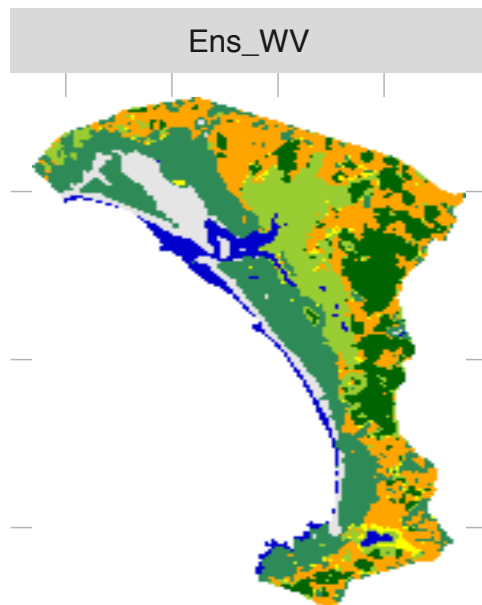

$495^{\prime} 000496000497^{\prime} 000498^{\prime} 000$ 
Figure 7 (on next page)

Habitat maps for 2016 obtained from each classification method.

amdai (Adaptive Mixture Discriminant Analysis), avNNet (Model Averaged Neural Network), gbm (Stochastic Gradient Boosting), knn (k-Nearest Neighbours), mda (Mixture Discriminant Analysis), pls (Partial Least Squares), rf (Random Forest), svmPoly (Support Vector Machines with Polynomial Kernel), svmRadial (Support Vector Machines with Radial Basis Function Kernel), svmLinear (Support Vector Machines with Linear Kernel), simply voting ('Ens_SV') and weighted voting ('Ens_WV') ensemble approaches. 

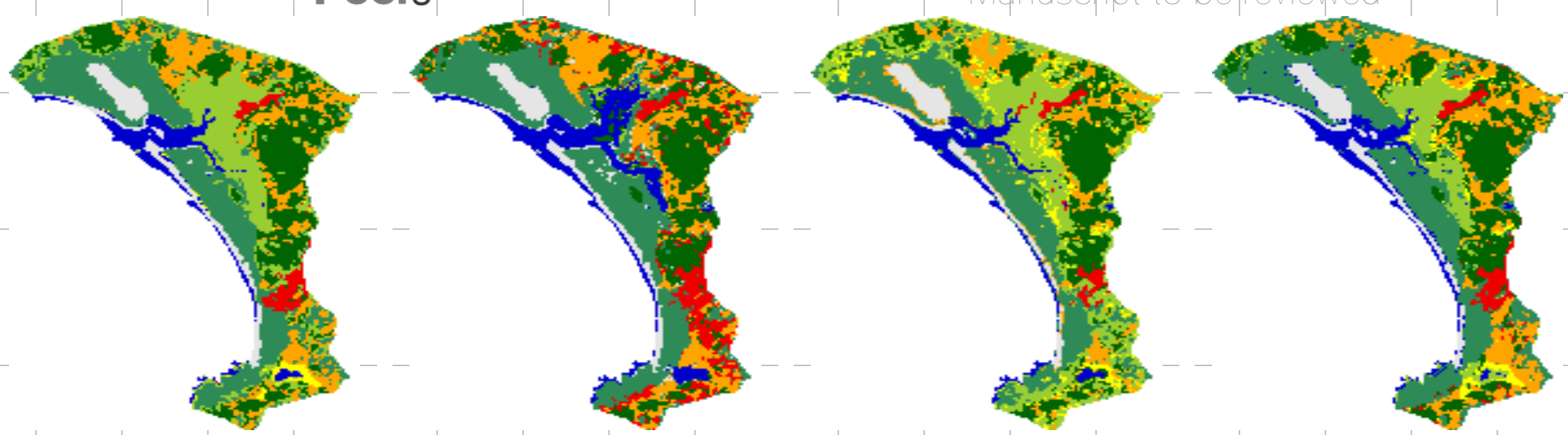
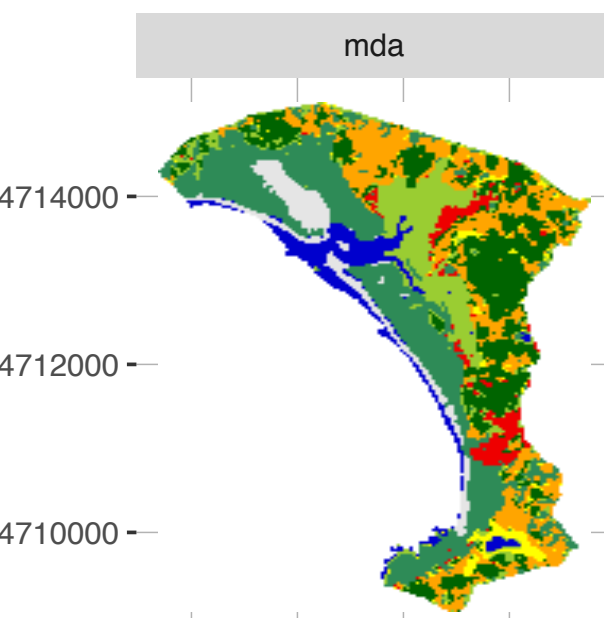

$$
\text { svmPoly }
$$

$4714000-$

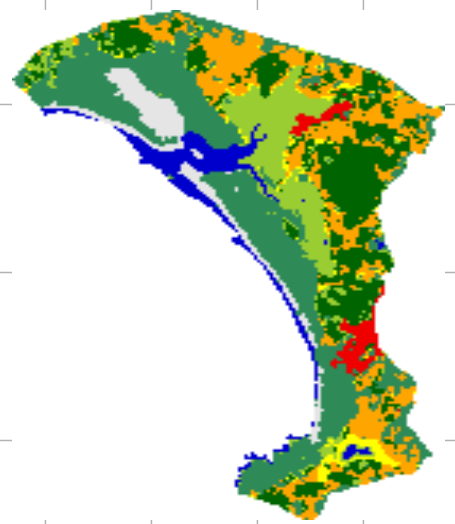

$495^{\prime} 0004966^{\prime} 000497^{\prime} 000498000$
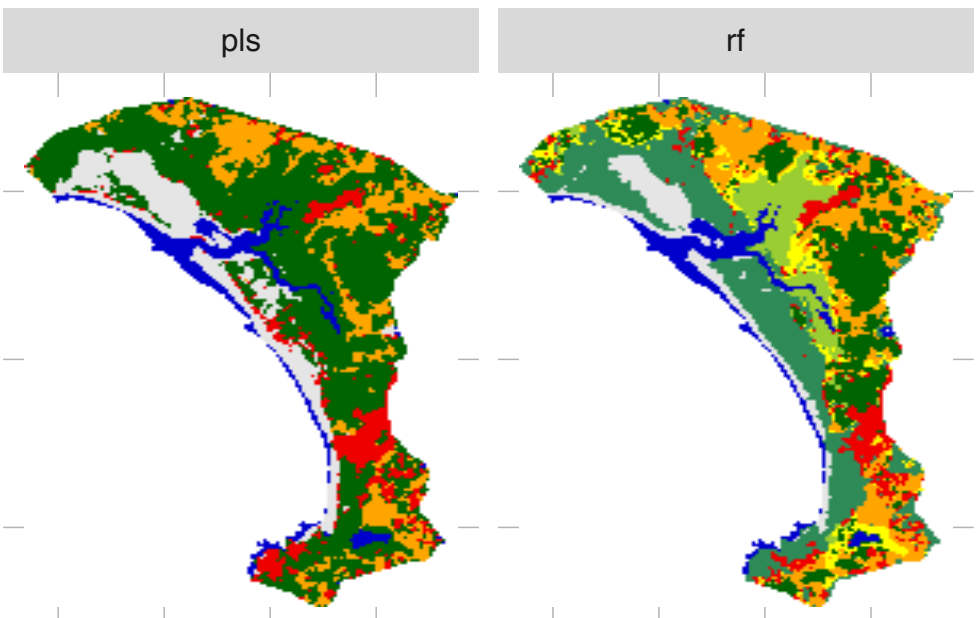

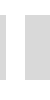

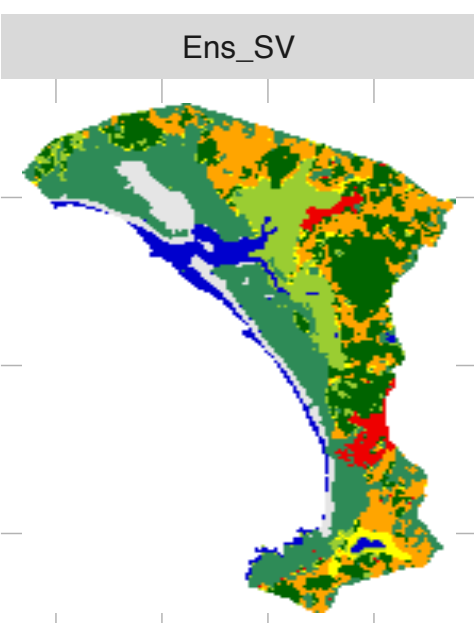

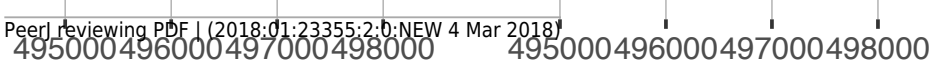
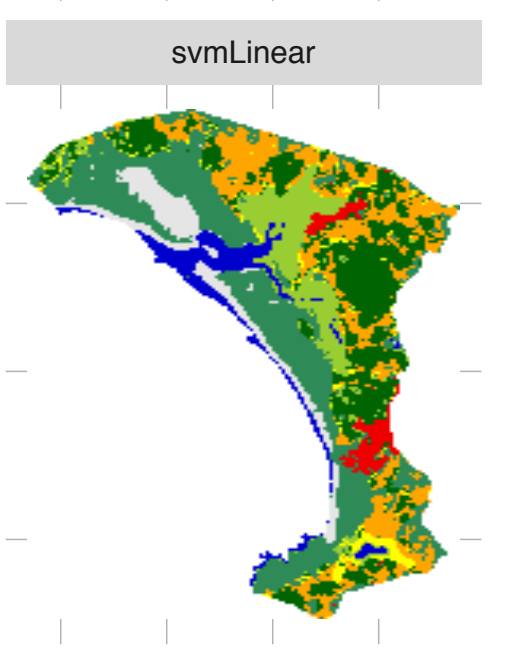

Habitats 2016
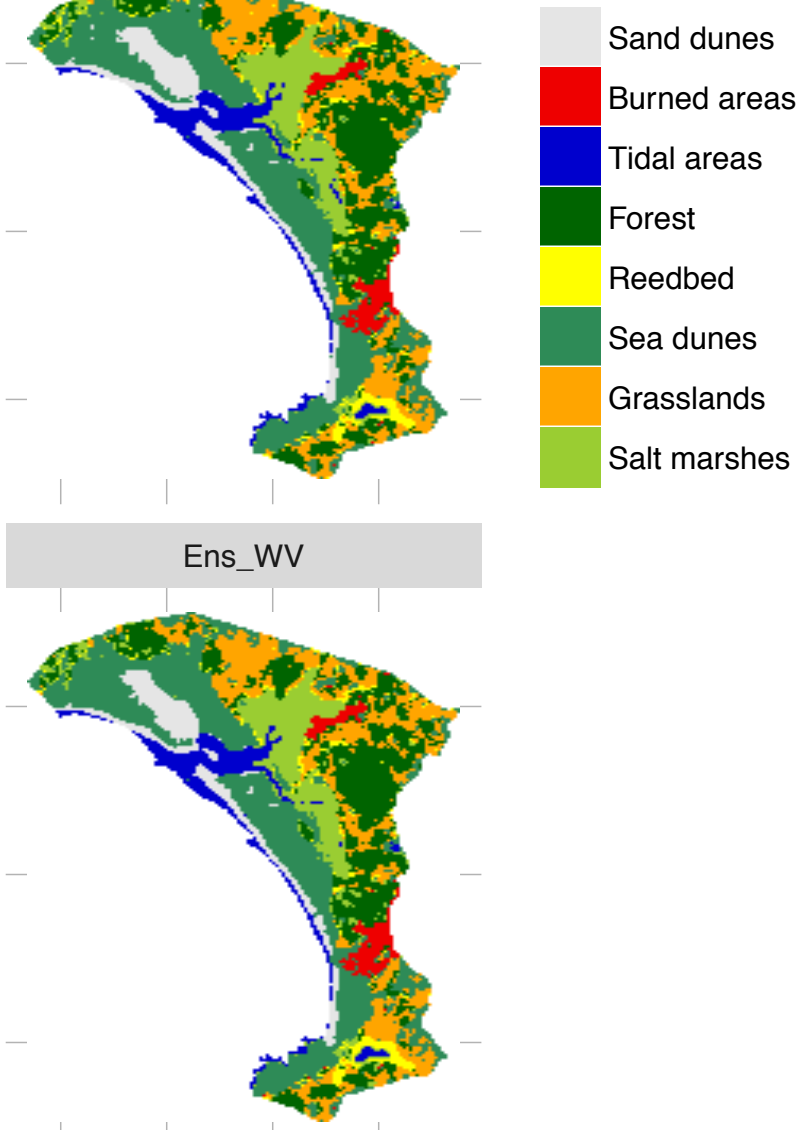

495000496000497000498000 